\title{
Seismic site response of submarine slope offshore southwestern Taiwan
}

\author{
Jing-Yi Lin ${ }^{1,2, *}$, Yen-Fu Chen ${ }^{1}$, Chih-Chieh Su ${ }^{3}$, Shao-Jinn $\mathrm{Chin}^{1,2}$, Win-Bin Cheng ${ }^{4}$, Wen-Nan Wu ${ }^{1,2}$, \\ Chin-Wei Liang ${ }^{1,2}$, Hsin-Sung Hsieh ${ }^{5}$, Shu-Kun Hsu ${ }^{1,2}$, and Yi-Chin Lin ${ }^{1,2}$ \\ ${ }^{I}$ Department of Earth Sciences, National Central University, Taoyuan City, Taiwan \\ ${ }^{2}$ Center for Environmental Studies, National Central University, Taoyuan City, Taiwan \\ ${ }^{3}$ Institute of Oceanography, National Taiwan University, Taipei City, Taiwan \\ ${ }^{4}$ Jinwen University of Science and Technology, New Taipei City Taiwan \\ ${ }^{5}$ Marine Instrument Center, National Taiwan University, Taipei City, Taiwan
}

\begin{abstract}
Article history:
Received 30 September 2016

Revised 8 May 2017

Accepted 9 May 2017

Keywords:

Single-station method, H/V spectral method, Site seismic response, Submarine slope, Southwestern Taiwan offshore

Citation:

Lin, J.-Y., Y.-F. Chen, C.-C. Su, S.-J. Chin, W.-B. Cheng, W.-N. Wu, C.-W. Liang, H.-S. Hsieh, S.-K. Hsu, and Y.-C. Lin, 2018: Seismic site response of submarine slope offshore southwestern Taiwan. Terr. Atmos. Ocean. Sci., 29, 51-63, doi: 10.3319/ TAO.2017.05.09.01
\end{abstract}

\begin{abstract}
Widely distributed Bottom-Simulating Reflectors (BSRs) have been observed in the area offshore of southwestern Taiwan where the active accretionary complex meets with the passive China continental margin. In order to clarify the link between seismic site response and sedimentary properties of submarine slope, we evaluate the response of seafloor sediments in regard to passive dynamic loads. The local site effect produced by shallow marine sediments was characterized by estimating the horizontal-to-vertical $(\mathrm{H} / \mathrm{V})$ spectral ratios of data recorded by the short-period Ocean Bottom Seismometers (OBSs). The results show that the maximal $\mathrm{H} / \mathrm{V}$ ratios appeared in the range of $3.66-9.28 \mathrm{~Hz}$, suggesting that the fundamental frequency is dominated by the effect related to the very shallow sediments. For most stations, the $\mathrm{H} / \mathrm{V}$ ratios estimated based on the earthquakes and noise records were characterized by different patterns. Relatively broad H/V pattern was obtained when the signals were extracted from earthquakes. This phenomenon may be related to soil nonlinearity when a stronger motion applies. In comparison with the available geological structures and bulk density distribution obtained from coring experiments, we found a relatively higher fundamental frequency of about $8-9 \mathrm{~Hz}$ for the more rigid material, such as mud diapir and folding axes. For most of the area along the slope, the fundamental frequency shows a relatively low value, about $6-8 \mathrm{~Hz}$. Finally, when a site is characterized by thick or lowest bulk density sedimentary layer, we observed a fundamental frequency lower than $5 \mathrm{~Hz}$, which is the lowest in our assessment.
\end{abstract}

\section{INTRODUCTION}

The southwestern offshore area of Taiwan, located in the northeastern part of the South China Sea, is characterized by wide-spread occurrence of bottom simulating reflectors (BSRs), indicating the potential existence of gas hydrates (Chuang et al. 2006; Jiang et al. 2006; Liu et al. 2006; Yang et al. 2006). The presence of gas-hydrate in the submarine sediment could vary its physical properties. The gas-hydrate dissociation induced by the human or non-human activities, such as gas hydrate exploration, change of temperature, pressure and sea level, etc., may weaken the marine sedimentary strength and cause serious slope instability prob-

\footnotetext{
* Corresponding author

E-mail:jylin.gep@gmail.com
}

lems (Kayen and Lee 1991; Sultan et al. 2004; Mienert et al. 2005; Haacke et al. 2008). In addition, the SW Taiwan lies at the northern termination of the Manila Trench active tectonic zone and is affected by the present-day geodynamic processes (Lin et al. 2008, 2009, 2015). The 2006 Hengchun earthquake of $\mathrm{M}_{\mathrm{L}} 7.0,44.1 \mathrm{~km}$ deep, occurred in the area and caused the interruption of a number of submarine cables (Hsu et al. 2008). Past and recent observations have shown that the intensity of ground motion during an earthquake is more important in sedimentary basins than on hard rock structures (Borcherdt 1970; Johnson and Silva 1981; Wen 1994; Wen and Peng 1998; Huang 2000, 2002; Koketsu and Kikuchi 2000; Komatitsch et al. 2004; Lee et al. 2009). Marine seafloor consists of substantial sediments, which could cover the hard rock feature and increase the ground motion. 
Therefore, how the seafloor sediments respond to the external driving forces and the influence of tectonic processes on the dynamics of gas hydrate systems should also be taken into account for the submarine hazards. In consequence, it is equaled important to understand the geological surface structures, as well as the site conditions, in regards to the site effect evaluation. To perform site investigation, drilling boreholes is the most conventional method, which can acquire detailed geotechnical information. However, it is expensive and time-consuming for the marine area. Different approaches related to the spectrum analysis have been applied to evaluate the local site response (Nakamura 1989; Lermo and Chávez-García 1993; Field and Jacob 1995). The principle is to evaluate spectral ratios, from which the peak site frequency (fundamental frequency) and the associated amplification factor could be determined. This method has been widely utilized for the onland area, including the determination of seismic microzonation (Bour et al. 1998; Lee et al. 2001; LeBrun et al. 2004), seismic site effect evaluation (e.g., Sokolov et al. 2007), bedrock depth mapping (Ibs-von Seht and Wohlenberg 1999), and shallow soil shear-wave velocity structure profiling (e.g., Scherbaum et al. 2003), etc. However, few studies have been introduced for the marine area, where site characterizations are even more difficult to investigate than those onland.
In this study, based on the OBS data acquired in 2013 and 2014, the evaluation of the local site effects for offshore southwestern Taiwan was conducted based on the most popular and world-wide approach through the calculation of the horizontal to vertical spectral ratio. Accompanied by the regional geological and coring results, we attempt to characterize the local sediment response for the marine area.

\section{GEOLOGICAL BACKGROUND}

Located in the transition from subduction to collision, the offshore southwestern Taiwan is characterized by a series of fold-and-thrust structures (Liu et al. 2006; Lin et al. 2008), the common structures in the convergent zone. Further to the west, a deformation front, extending from the northern tip of the Manila Trench, along the Penghu Canyon, to the frontal thrust of the Taiwan mountain belt on land (Liu et al. 1997, 2004), separates the passive China continental margin and the submarine Taiwan accretionary wedge. The horst-and-graben structures of the passive margin prevail with a ENE-WSW or E-W direction to its west (Sun 1982; Hu 1988; Yang et al. 1991). To its east, the accretionary wedge can be divided into upper-slope and lower-slope domains based on the seismic data (Reed et al. 1992; Liu et al. 1997; Lin et al. 2008) (Fig. 1). A series of

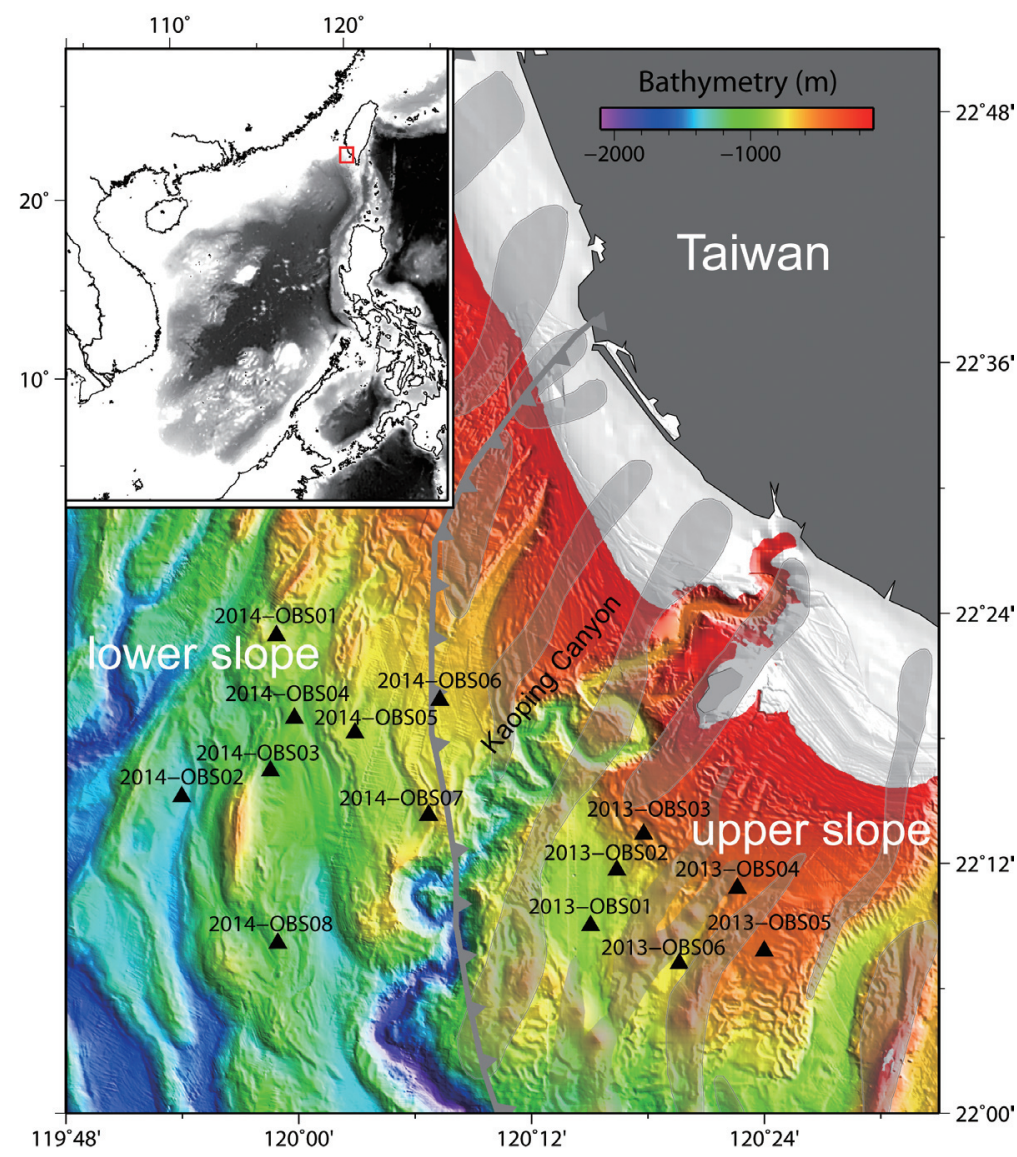

Fig. 1. General map and the positions of the OBS stations for the 2013 and 2014 experiments. Light shadow zones show the mud diaper determined by Chen et al. (2014). 
mud diapirs is found in the upper-slope domain (Sun and Liu 1993; Chiang and Yu 2006; Chen et al. 2010, 2014). The diapiric structures strike in a NE-SW direction, parallel to the structural trend of the folds and thrust faults, and can be traced to adjacent onshore structures (Chiu et al. 2006), indicating active fluid expulsion in the accretionary wedge. Otherwise, the lower-slope domain is characterized by a series of elongated submarine anticline ridges related to active thrusting and folding (Liu et al. 2004; Lin et al. 2008).

\section{METHOD AND DATA}

The method developed by Nakamura (1989) which introduced the horizontal-to-vertical (H/V) spectral ratio based on empirical observations was used for our study. Its basic assumption is that the vertical component of the ground motion would not be influenced significantly by the local site conditions. When $H_{B} / V_{B}$ is equal to 1 , where $H_{B}$ and $V_{B}$ are the amplitude spectrum of the horizontal and vertical component for the rock site, the site effect of sediment site can be estimated as $S_{E}$, which can be described as: $S_{E}=H_{S} / H_{B}$. In this equation, $H_{B}$ and $V_{B}$ are the amplitude spectrum of the horizontal and vertical component for the sediment site. Thus, the H/V can be obtained by dividing the horizontal spectra by the vertical spectral "reference" component. This technique has been described in a number of papers in detailed (Lermo and Chávez-García 1993; Teves-Costa et al. 1996; Bour et al. 1998; Fäh et al. 2001; Zhao et al. 2006). In the previous works, the technique was applied to weak and strong ground motions, which refer to the ambient noise and earthquake wave signal. They showed that the H/V spectral ratio clearly defines the resonance peaks, which are well correlated with the preferential vibration mode of the site in soft soil sites, and reveals the overall frequency dependence of the site response.

The passive Ocean Bottom Seismometer (OBS) data were acquired in the summer of 2013 and 2014. During the 2013 experiment, 6 OBSs were deployed in OR3-1672 cruise and recorded data from 28 March to 11 April 2013. However, one OBS, 2013-OBS01, has not been recovered successfully. In 2014, 8 OBSs were deployed by using the OR3-1756 cruise and have stayed on the seafloor between 18 April and 11 May 2014 to listen to the natural earthquake and noise signals. In this experiment, 2014-OBS04 was missed. The study area of the 2013 experiment was focus to the southern area of the Kaoping Canyon (KC); whereas the target moved to its northern part in 2014 (Fig. 1). The OBSs were deployed at a water depth between 442.35 and $1327.31 \mathrm{~m}$ with a sampling rate of $125 \mathrm{~Hz}$. The objectives of these projects were to learn about the seismic activity in the gas-hydrate potential sites and understand the change of site ground motion in response to the noise and earthquakes. Both experiments used MicrOBS Plus, an instrument developed by the French Research Institute for Exploitation of the Sea (Ifremer) (Auffret et al. 2004). These short-period type devices were packaged within a 17" glass sphere, which includes the electronics, the batteries and one threecomponent $4.5 \mathrm{~Hz}$ geophone (Geospace GS-11D). The instrument response for the geophones is shown in Fig. 2. One broadband-type hydrophone was also fixed on the instrument frame, $\sim 0.5 \mathrm{~m}$ above the seafloor. The coupling of the instrument to the sea bottom is extremely important. To further optimize the coupling of the instrument, a steel weight in the form of a cross with a U-profile, was used to ensure good penetration of the ballast weight into the seafloor. For the instrument deployment and recovery, the OBSs descended to the sea floor and were released by electrolysis of a burn wire attached to ballast weights and triggered by an acoustic signal from the ship. After downloading the data, visual inspection was performed to determine the $\mathrm{P}$ - and $\mathrm{S}$ arrivals, based on which we determined the data windows for the frequency domain analysis (Fig. 3). A 10-s time window before the arrival of P-wave and following directly the $\mathrm{S}$-wave were selected to estimate the effect of the ambient
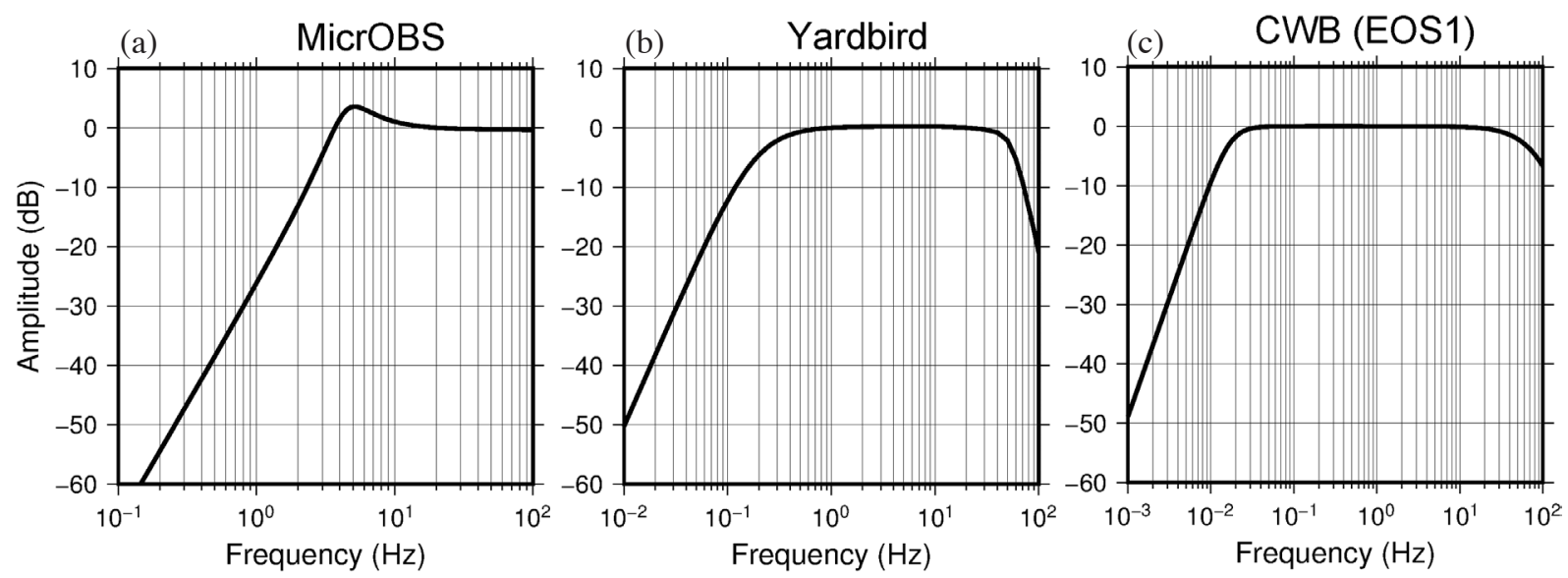

Fig. 2. Geophone response of (a) MicrOBS, (b) Yardbird type OBS (YB2), and (c) the CWB submarine cable (EOS1). 


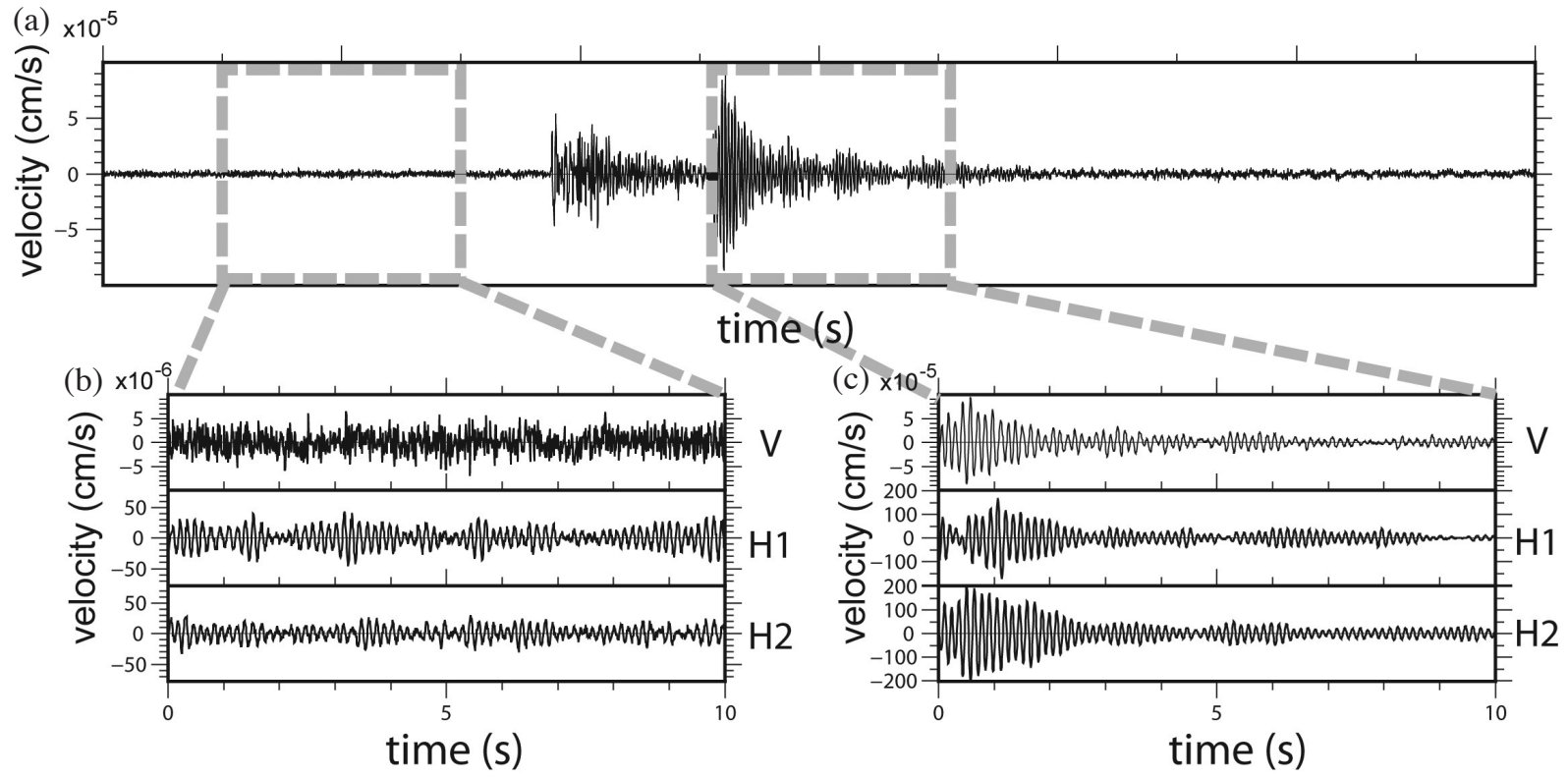

Fig. 3. Example for the selection of time windows used in our analysis. In (a), the waveform shows the vertical component for one earthquake recorded by 2014-OBS05. The two gray dashed squares are the 10-sec time windows that we selected for the H/V calculation. (b) and (c) demonstrate the waveform in the three components, which are vertical (V), horizontal 1 (H1), and horizontal 2 (H2).

noise and the earthquakes signals (Fig. 3a). For the ambient noise analysis, we avoided the time periods with any transient signals. While visually inspecting the records, the existence of several local, regional, and teleseimic events were clearly evident. In total, we determined 47 and 149 earthquakes for the 2013 and 2014 OBS experiments for a recording period of 12 and 23 days (Fig. 4). Significant differences in signals levels between horizontal and vertical components were evident (Figs. $3 b$ and c). The amplitude of the two horizontal components had similar magnitude for both the ambient noise and earthquake signals. For the ambient noise, the signal amplitude for the horizontal component is about $5.0 \times 10^{-5} \mathrm{~cm} \mathrm{~s}^{-1}$, whereas the signals recorded in the vertical component only had the one-tenth of those recorded by the horizontal ones (Fig. 3b). The amplitude for the earthquake records were of the order of magnitude of $10^{-3} \mathrm{~cm} \mathrm{~s}^{-1}$ for the horizontal components. However, the amplitude could be drop to the order of $10^{-5} \mathrm{~cm} \mathrm{~s}^{-1}$ for the vertical one (Fig. 3c). Based on these time series data, the Fourier amplitudes were calculated using cosine-tapering (1 second at each end) before transformation and smoothed with triangular moving Hanning window $(0.25 \mathrm{~Hz})$ in the $0.1-20 \mathrm{~Hz}$ frequency band for each of the three components at each site. Finally, the root mean square of the two horizontal components was calculated to produce the horizontal spectra (Yamanaka et al. 1994), which was then divided by the vertical component to obtain the $\mathrm{H} / \mathrm{V}$ ratio. As each earthquake can provide a set of data, we estimated the final $\mathrm{H} / \mathrm{V}$ curve of each station by calculating the average of the value obtained for each station (Figs. 5 and 6). We can notice that the behavior of most $\mathrm{H} / \mathrm{V}$ curves for the same site were similar, even though the data was extracted from different time windows. This observation suggests that our result is robust.

\section{RESULTS}

The H/V curves determined from the onland seismic data can be categorized into several general types (LeBrun et al. 2004). Similar patterns can also be observed for the H/V curves estimated from the ambient noises based on the OBS records. Some OBSs stations show a sharp distribution, with predominant frequency peak that is easy to define, e.g., 2013OBS03, 2013-OBS05, 2014-OBS03, 2014-OBS07, and 2014-OBS08 (Figs. 5 and 6). Other stations, such as 2013OBS02, 2013-OBS04, 2014-OBS01, and 2014-OBS06, the $\mathrm{H} / \mathrm{V}$ curve is broad and the predominant frequency is not as distinct. In these cases, the predominant frequency was determined when the amplification is maximal. Three stations, 2013-OBS06, 2014-OBS02, and 2014-OBS05, have a rough $\mathrm{H} / \mathrm{V}$ pattern, with some amplification displayed but the predominant period is not clearly defined. In this case, the average $\mathrm{H} / \mathrm{V}$ ratio which has the largest value was taken to be the fundamental frequency. The peak frequency and its corresponding $\mathrm{H} / \mathrm{V}$ amplitude are indicated in Tables 1 and 2 . With regard to the $\mathrm{H} / \mathrm{V}$ curves calculated based on the earthquake signals, a relatively broader distribution and greater amplification were revealed. The fundamental frequency became less evident. Generally, the H/V spectral ratios of the OBS obtained from the ambient noise indicate that the 

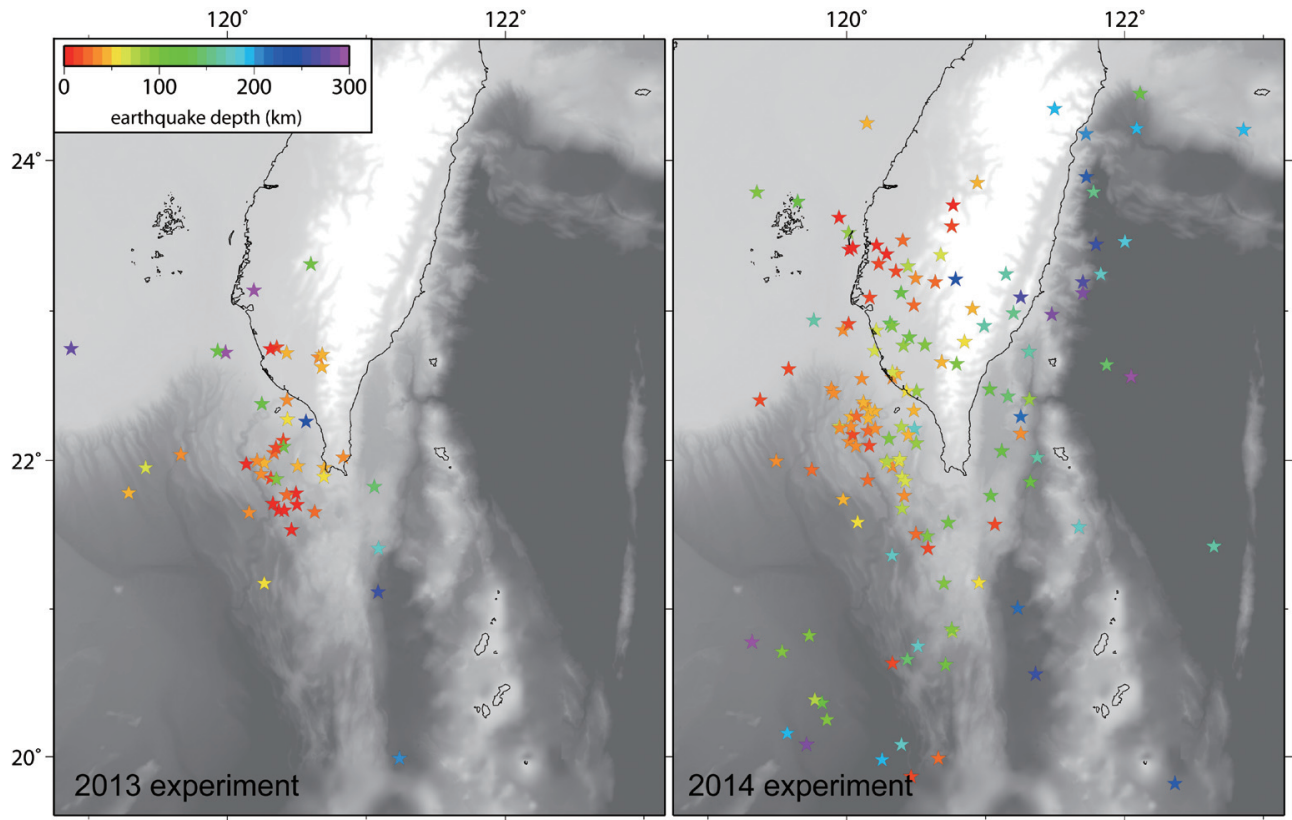

Fig. 4. Distribution of epicenters of earthquakes used in this study for the 2013 and 2014 experiment. Color shows the focal depth.

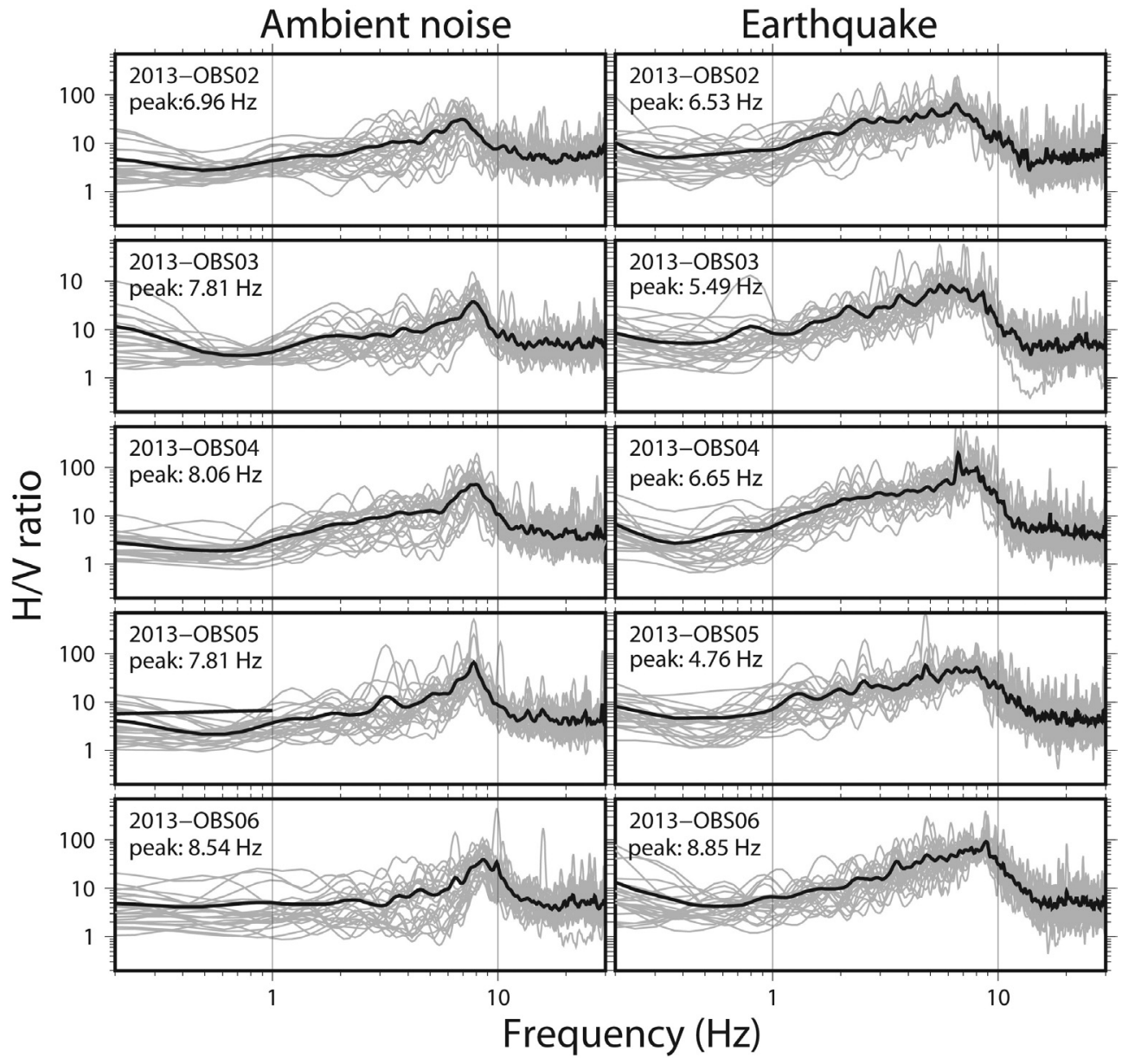

Fig. 5. The H/V curves calculated based on the pre-event ambient noise and the earthquake signals for the 2013 OBS experiments. The black line shows the average. 


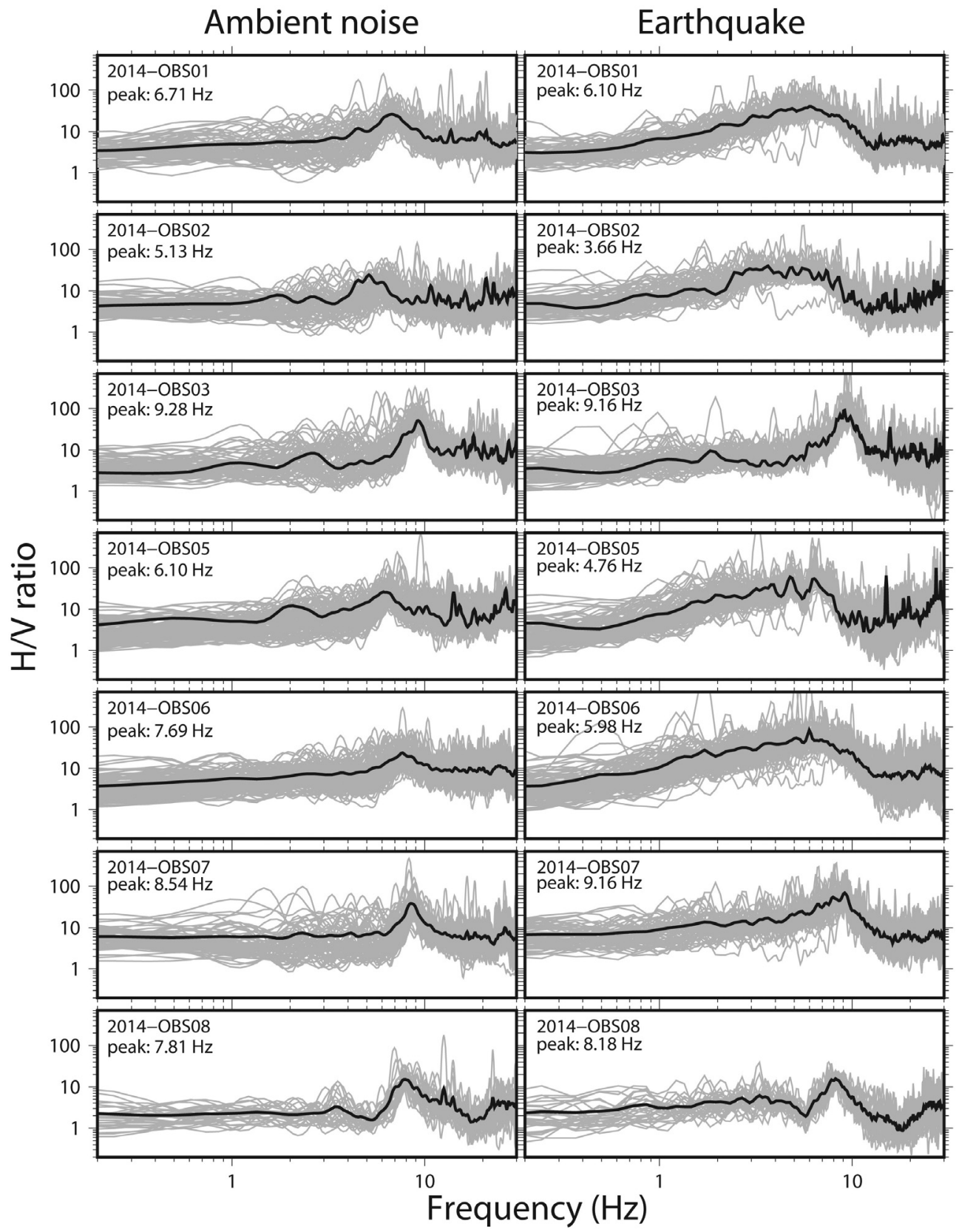

Fig. 6. The H/V curves calculated based on the pre-event ambient noise and the earthquake signals for the 2014 OBS experiments. The black line shows the average.

Table 1. Fundamental frequency, amplitude and bulk density estimated from 2013 experiment.

\begin{tabular}{c|c|c|c|c|c}
\hline \multirow{2}{*}{ Station } & \multicolumn{2}{|c|}{ ambient noise } & \multicolumn{2}{c|}{ earthquake } & \multirow{2}{*}{ bulk density $\left(\mathbf{g ~ c m}^{-3}\right)$} \\
\cline { 2 - 5 } & peak frequency $(\mathbf{H z})$ & amplitude & peak frequency $(\mathbf{H z})$ & amplitude & \\
\hline 2013-OBS02 & 6.96 & 31.48 & 6.53 & 65.49 & 1.58 \\
2013-OBS03 & 7.81 & 37.40 & 5.49 & 83.94 & 1.66 \\
2013-OBS04 & 8.06 & 44.89 & 6.65 & 194.11 & 1.60 \\
2013-OBS05 & 7.81 & 65.70 & 4.76 & 58.16 & 1.63 \\
2013-OBS06 & 8.54 & 38.73 & 8.85 & 92.56 & 1.70 \\
\hline
\end{tabular}


Table 2. Fundamental frequency, amplitude and bulk density estimated from 2014 experiment.

\begin{tabular}{c|c|c|c|c|c}
\hline \multirow{2}{*}{ Station } & \multicolumn{2}{|c|}{ ambient noise } & \multicolumn{2}{c|}{ earthquake } & \multirow{2}{*}{ bulk density $\left(\mathrm{g} \mathrm{cm}^{-3}\right)$} \\
\cline { 2 - 5 } & peak frequency $(\mathbf{H z})$ & amplitude & peak frequency $(\mathbf{H z})$ & amplitude & \\
\hline 2014-OBS01 & 6.71 & 26.24 & 6.10 & 40.87 & 1.69 \\
2014-OBS02 & 5.13 & 24.09 & 3.66 & 39.69 & 1.56 \\
2014-OBS03 & 9.28 & 51.59 & 9.16 & 90.55 & 1.63 \\
2014-OBS05 & 6.10 & 26.02 & 4.76 & 60.40 & 1.70 \\
2014-OBS06 & 7.69 & 23.53 & 5.98 & 83.54 & 1.68 \\
2014-OBS07 & 8.54 & 38.26 & 9.16 & 68.96 & 1.73 \\
2014-OBS08 & 7.81 & 15.14 & 8.18 & 15.60 & 1.74 \\
\hline
\end{tabular}

dominant frequency is in the range of approximately 5.13 $9.28 \mathrm{~Hz}$ (Figs. 5 and 6; Tables 1 and 2) and the amplification spreads from 15.14 - 65.70. Even though similar frequency values, ranging from $3.66-9.16 \mathrm{~Hz}$, could also be observed for the H/V curve calculated from the earthquake signals, the dominant frequency is generally lower than those obtained from ambient noise (Figs. 5 and 6; Tables 1 and 2). In contrast, the $\mathrm{H} / \mathrm{V}$ amplification is much greater under the influence of earthquakes, which has an average of about 60 and can reach as high as 194.11 for 2013-OBS04. Basically, no significant difference regarding the $\mathrm{H} / \mathrm{V}$ distribution for the two different study areas was found.

\section{DISCUSSION}

\subsection{The Origin of the Fundamental Frequency}

As similar fundamental frequency can be found for all the OBSs, the instrument response could be the suspect for the origin of these ground motion manifestation. The instrument response of the OBSs shows that the predominant frequency at the range of $5.13-9.28 \mathrm{~Hz}$ estimated from our study should still in the instrument recording capacity (Fig. 2a). However, in order to further certify that the predominant frequency was not instrumental artifacts, we put our instrument on the solid cement ground to record the ambient noise for several hours and then estimated the H/V based on this onland record (Fig. 7). The H/V estimation shows a predominant peak of $12.99 \mathrm{~Hz}$, which largely varies from those estimated by the OBS deployed at sea (Figs. 5 - 7). Based on the conventional equation introduced by Dobry et al. (1976), we could estimate the depth of the contrast boundary from the peak frequency value. The equation can be described by $\mathrm{F}=\mathrm{v} / 4 \mathrm{~h}$, where $\mathrm{F}, \mathrm{v}$ and $\mathrm{h}$ represent the dominant frequency, shear-wave velocity and the thickness of the contrast boundary, respectively. The solid cement ground, usually made up by 1 or $2 \mathrm{~m}$ of cement, may produce a strong contrast boundary at very shallow depth and generate a $\mathrm{H} / \mathrm{V}$ peak at higher frequency band. Thus, instead of the instrument response effect, the fundamental frequency obtained based on the OBSs data should reflect truly the H/V characteristic of the ground motion. For another aspect, even though several previous studies have shown that the use of short-period instrument is appropriate to estimate the $\mathrm{H} / \mathrm{V}$ characteristics, it could be still uncertain if a short-period type instrument can reveal the amplification of the signals occurred at the low frequency band due to instrument response. To clarify this point, we estimated the $\mathrm{H} / \mathrm{V}$ curve based on the records of Yardbird OBS, a product developed by the engineering team formed between IES (Institute of Earth Sciences, Academia Sinica), IUT (Institute of Undersea Technology, National Sun Yat-san University), and TORI (Taiwan Ocean Research Institute). Yardbirds is equipped with an upgraded geophone sensor with flat velocity response up to $3 \mathrm{~s} \mathrm{(Fig.} \mathrm{2b),} \mathrm{which} \mathrm{allow} \mathrm{recording}$ the signals of relatively much lower frequency in regards to the OBS used in our study. In addition, the sensor package of the Yardbird type OBS is separated from the system package, whereas the geophone sensor is integrated in the glass sphere for our OBSs. The comparison between the analyses obtained from the data recorded by the two types of instruments could help to clarify if our results were affected by the instrument response or coupling problem with the ground. However, none of Yardbird type OBS has been deployed in our study area. We thus chose the data recoded by a Yardbird OBS deployed at a similar water depth in the Okinawa Trough $\left(\mathrm{YB} 02 ; 122.5^{\circ} \mathrm{E}, 2^{\circ} \mathrm{N} ; 1524 \mathrm{~m}\right.$ deep) for the comparison. As the result, the H/V curve of YB02 showed a dominate frequency peak at $7.56 \mathrm{~Hz}$, which is in the frequency range obtained in our study (Fig. 7). Therefore, we suggest that this fundamental frequency range has no relation with the instrument type, either with the shape of instruments. The peak frequency was actually influenced by the ground motion of the seafloor.

Experimental data shows that the thickness of the contrast boundary in the sediments affects the value of the fundamental frequency. We used the conventional equation introduced by Dobry et al. (1976), already discussed in the previous paragraph, to estimate the depth of the contrast boundary. The H/V curves obtained based on the OBS ambient noise record for the 2014 study area show the dominant 
frequency ranges between 5.13 and $9.28 \mathrm{~Hz}$. In addition, Cheng et al. (2014) obtained the shear-wave velocity model in our study area based on the seismic reflection data, which has a value vary from $320-580 \mathrm{~ms}^{-1}$ for the shallow part of the sedimentary layers. In consequence, the estimated thickness should be between 8.6 and $40.3 \mathrm{~m}$, which is relatively thin compared to the depth of sedimentary basin reported by some seismic profiles. This estimation infers that the fundamental frequency of the marine sediments is mainly controlled by the unsolidified sediments located on the top of the seafloor. To examine this assumption, we calculated the H/V ratios based on the data recorded by the cable-based ocean bottom seismographic observatory, named "Marine Cable Hosted Observatory" (MACHO) (Hsiao et al. 2014). The installed instruments of the observatory include a broadband seismometer (EOS1), which is fixed to the seafloor and buried in the marine sediments. Figure $2 \mathrm{c}$ shows its instrument response. Its $\mathrm{H} / \mathrm{V}$ curve shows that no specific amplification exists for the frequency higher than $1 \mathrm{~Hz}$ and only a small rise at the frequency of about $0.17 \mathrm{~Hz}$. Thus, we suggest that if the instrument is buried into the sediment, it would not be affected by the shallow sedimentation and no fundamental frequency appears at the frequency band higher than $1 \mathrm{~Hz}$. It is worth noting that the $\mathrm{H} / \mathrm{V}$ spectral ratio of ambient noise is usually correlated to the average $\mathrm{S}$-wave velocity in the top $30 \mathrm{~m}$, which is refer to Vs30. Based on a analysis in the southwestern Taiwan inland area, Kuo et al. (2015) defined a linear correlation between Vs30 and the dominant frequency. In their study, the class $\mathrm{C}$, characterized by a Vs30 in the range of $360-760 \mathrm{~m} \mathrm{~s}^{-1}$, processes similar fundamental frequency as our study. This coincidence may also suggest that the $\mathrm{H} / \mathrm{V}$ distribution estimated by the OBS should indeed be caused by the sediments at shallower depth, probably less than $30 \mathrm{~m}$.

On the other hand, we noticed that the H/V ratios estimated based on the earthquakes and noise records were characterized by different patterns. Relative broad H/V pattern was obtained when the signals were extracted from earthquakes. Peaks in the H/V spectral ratios can be generated by the resonances in the uppermost layers if high impedance contrasts are present in soil structure. Otherwise, if impedance contrasts are weak (Malischewsky and Scherbaum 2004) or if several layers are present, the spectral ratio shows more complex pattern. This phenomenon may be linked to the soil nonlinearity effect during strong motions. The effect usually makes dominant frequencies shift to lower frequency and may result in a relative broad $\mathrm{H} / \mathrm{V}$ distribution. Otherwise, the locations and depths of hypocenters may cause different $\mathrm{H} / \mathrm{V}$ pattern like the case in the Taipei Basin (Sokolov et al. 2009). However, the behaviors of most $\mathrm{H} / \mathrm{V}$ curves for the same site were similar (Figs. 5 and 6). Therefore, soil nonlinearity seems to be the better candidate to explain this observation. Unfortunately, the earthquakes recorded by our OBS network were not able to be located precisely and cannot provide enough information for related analyses.

\subsection{Comparison with the Surface Geology and Bulk Density}

Even though the study area of 2013 experiment occurred in the upper slope domain and the 2014 one in the lower slope domain (Fig. 1), the H/V curves from the two datasets do not expose significant differences. It may suggest that the basic sediment composition and structural units should be similar for the two geological areas. The upper slope area is characterized by a series of mud diapir, whereas the lower slope has numerous fold and thrust structures which could be recognized by the ridge form bathymetry. All these ridge axes and mud diapir represent the outcrop of high density material and generally have relatively larger rigidity with regard to the normal seafloor sediments (Doo et al. 2015). In the 2013 experiment, all the OBSs were located on the sedimentary basins located in between the mud diapir to avoid the large slope gradient (Fig. 1). The fundamental frequency has similar distribution between about $7-8 \mathrm{~Hz}$,

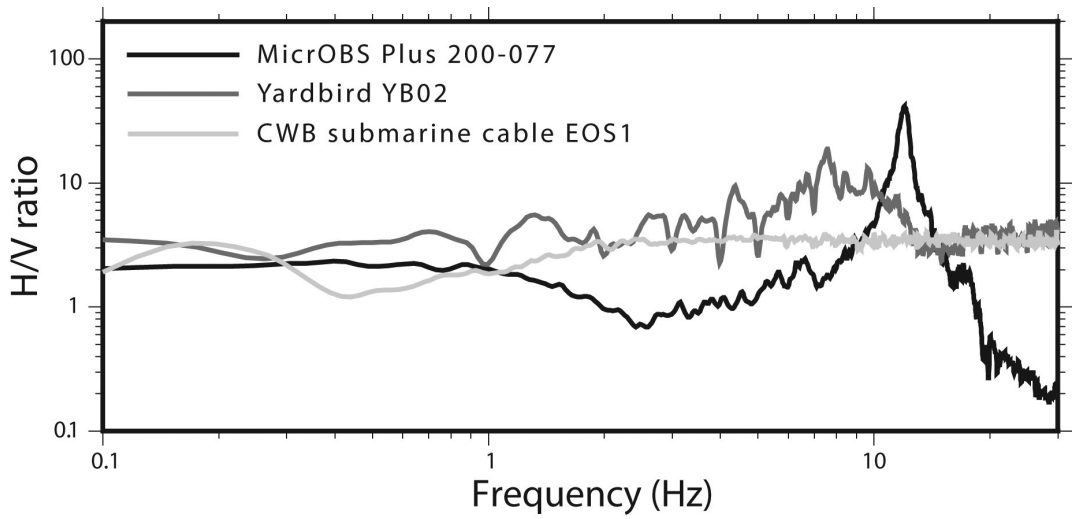

Fig. 7. The H/V curves calculated based on the waveform data extracted from the onland MicrOBS (OBS200-077), Yardbird type OBS (YB2), and the CWB submarine cable (EOS1). 
except for 2013-OBS06, which is located between two close mud diapirs. However, several OBSs were deployed on the top of ridges for the 2014 experiment, such as 2014-OBS03, 2014-OBS07, and 2014-OBS08 (Fig. 1) and all these three stations possessed a relatively higher fundamental frequency, even more than $9 \mathrm{~Hz}$. In addition, almost no variation between the $\mathrm{H} / \mathrm{V}$ curves obtained from the ambient noise and earthquake movement, suggesting that the direct contact with the rock bed decrease the amplified effect of multiple sedimentary contrasts. Otherwise, other OBSs for the 2014 experiments were located in a relatively flat area and the fundamental frequency was smaller.

Figure 8 shows the bulk density distribution obtained based on the coring samples acquired from several experiments (Su et al. 2016). We can observe that almost all the OBS were deployed along the slope, where bulk density has relatively smaller value compared to those along the coastline or the Kaoping Canyon. The lowest bulk density, about $1.56 \mathrm{~g} \mathrm{~cm}^{-3}$ was located in the vicinity of 2014-OBS02 (Fig. 9, Tables 1 and 2). Coincidently, the lowest fundamental frequency occurred also at the station, which has a value less than 6 and $4 \mathrm{~Hz}$ for the result from ambient noise and earthquake signals. This phenomenon suggests that the fundamental frequency could be actually affected by the composition of sediments. In consequence, we propose that the hardest area should have the highest dominant fundamental frequency. On the contrary, the lowest fundamental frequency should happen in the area whether the sedimentary cover is soft and thick (Figs. 9a and b; Tables 1 and 2). We observed that the positive correlation between the fundamental frequency and the corresponding bulk density was better illustrated for the 2013 experiment. This could be due to the coring site distribution shown as black crosses in Fig. 8, which provided a better constraint for the estimation of bulk density in that area. In contrast to the relationship between the fundamental frequency and the bulk density, no specific relation was demonstrated between the $\mathrm{H} / \mathrm{V}$ amplitude and the bulk density (Figs. 9c and d; Tables 1 and 2). This observation may suggest that the value of $\mathrm{H} / \mathrm{V}$ ratio less depend on the ground material but the magnitude of ground motion. However, this reasoning should be verified with further investigation. On the other hand, please note that the amplitude for the $\mathrm{H} / \mathrm{V}$ estimated based on the OBS data have relatively larger values with regard to those estimated on land. Particularly, an obvious increase of amplitude occurred for the $\mathrm{H} / \mathrm{V}$ calculated from the earthquake data, which can reach as high as 156.85 . As the marine sediment contains substantial amount of water, which may decrease the cohesive force between the sediment grain and facilitate its horizontal movement with strong motion.

\section{CONCLUSION}

For the past decades, many investigations have been performed to obtain the ground motion characteristics in regards with the earthquake shaking at inland sites.

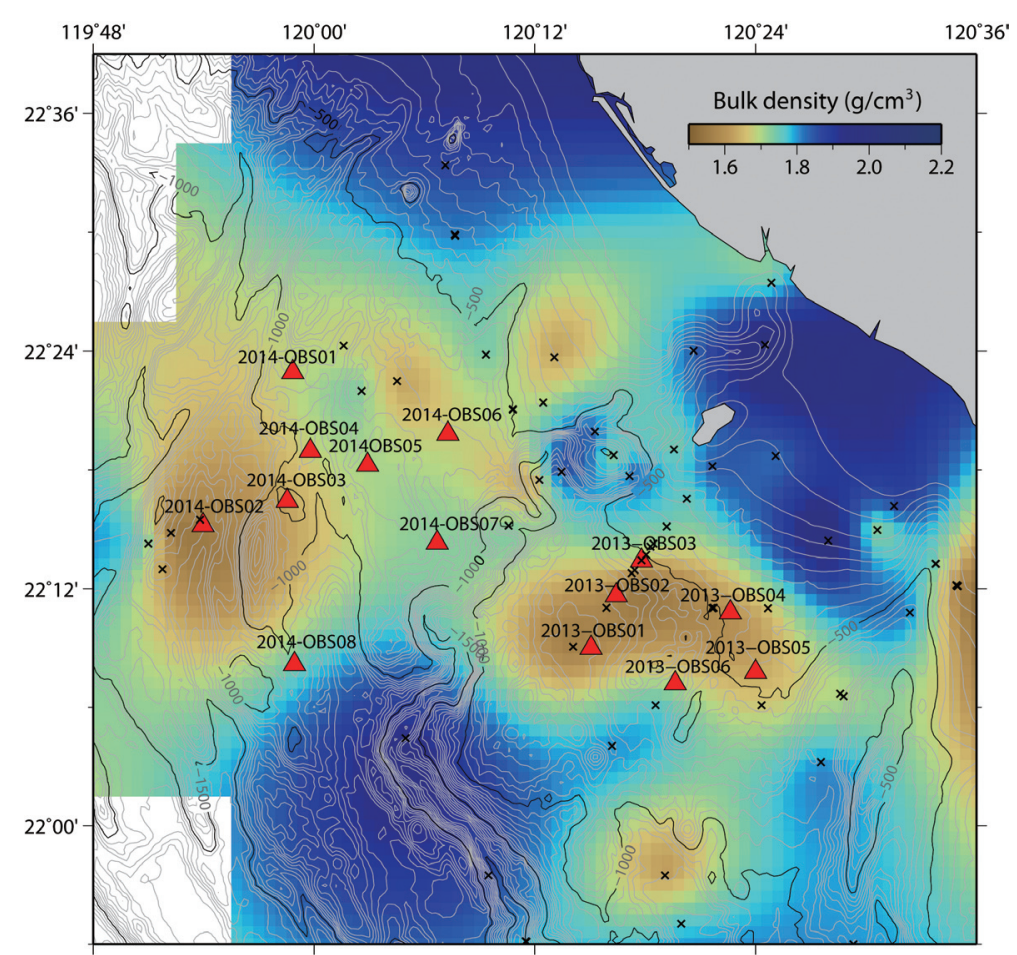

Fig. 8. The bulk density distribution calculated based on the coring data. Red triangles are the OBS positions for the 2014 and 2013 experiments. Blues crosses show the shallow coring positions. 

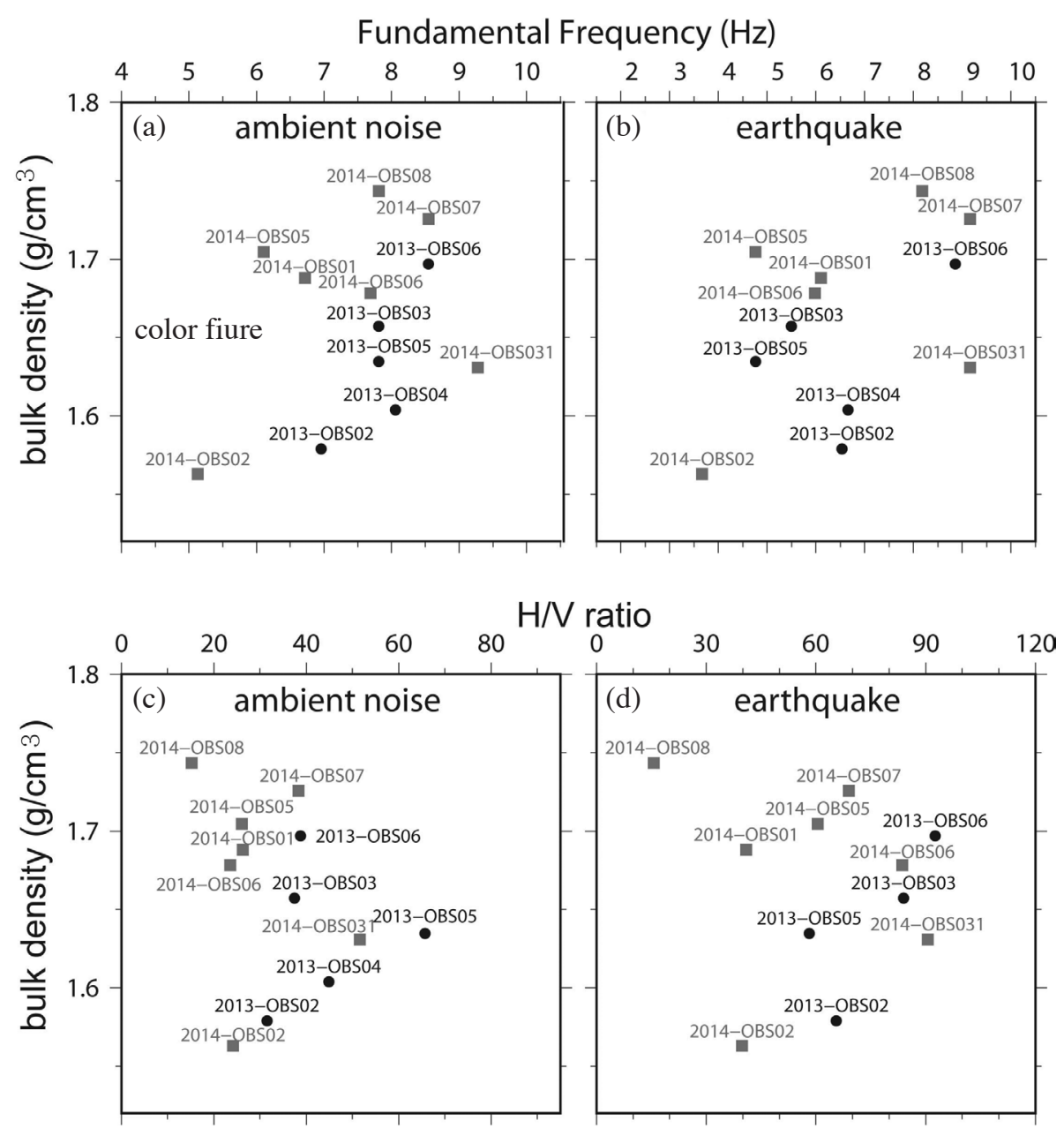

Fig. 9. Comparison of the fundamental frequency with the bulk density for the (a) ambient noise and (b) earthquake. Comparison of the H/V amplitude of the peak frequency and bulk density for the (c) ambient noise and (d) earthquake.

Relative less knowledge was acquired for the marine sediments. However, with the fast development in the submarine infrastructures in response to the energy exploration and environmental protection needs, such as marine wind turbine, submarine cable and gas-hydrate/mineral exploration, it is important to use the seafloor motions as the basis for the seismic design of these submarine infrastructures. In this study, the local site effect produced by shallow marine sediments was characterized by estimating the H/V spectral ratios based on the data recorded by the short-period OBSs to clarify the link between seismic site response and sedimentary properties of submarine slope. We evaluate the response of seafloor sediments in regard to passive dynamic loads, including the ambient noise as well as earthquake signals. The results show that the maximal $\mathrm{H} / \mathrm{V}$ ratios of all the OBS stations appeared in the range of $5.13-9.28 \mathrm{~Hz}$ for the ambient noise and $3.66-9.16 \mathrm{~Hz}$ for the earthquake signals. The depth of the estimated velocity contrast is about 8 - $39 \mathrm{~m}$, suggesting that the fundamental frequency for the seafloor is dominated by very shallow sediment. For most stations, the $\mathrm{H} / \mathrm{V}$ ratios estimated based on the earthquakes (i.e., strong input signal) and ambient noise (i.e., background, micro-seismic noise) records were characterized by different patterns. Usually, no distinct peak is observed for the $\mathrm{H} / \mathrm{V}$ curves calculated during earthquakes. This phenomenon may suggest that boundary exist when a stronger motion applies. In comparison with the geological structures and bulk density distribution obtained from coring experiments, we found that the fundamental frequency for the rigid material, such as mud diapir, is relatively higher, about $8-9 \mathrm{~Hz}$. For most areas along the slope, the fundamental frequency shows relatively low value, about 6 - $8 \mathrm{~Hz}$. Finally, when a site is characterized by thick or soft sedimentary layer, we observed a fundamental frequency of about $5 \mathrm{~Hz}$, which is the lowest in our assessment. This spectral feature exhibits a gross correlation with the site geological conditions, which is used as qualitative index of the soil characteristics.

OBSs have been widely used over the past decades to collect natural earthquake data for seismic monitoring of the submarine geological structures or to receive the active 
seismic sources to image the underground velocity distribution. Our study shows that they could also provide ground motion information which is very important for the marine geo-hazard assessment.

Acknowledgements We would like to express our gratefulness to the National Energy Program (NEP) of Taiwan, provided funding for this research. The captains and crew of R/V Ocean Researcher 1 and Ocean Researcher 3 are appreciated for shipboard assistance. We also thank the editor and the two anonymous reviewers for their helpful comments. Support from the Ministry of Science and Technology (MOST), Taiwan, under contract No. 106-3113-M-008-001 and 106-2116-M-008-006 is gratefully acknowledged.

\section{REFERENCES}

Auffret, Y., P. Pelleau, F. Klingelhoefer, L. Geli, J. Crozon, J. Y. Lin, and J.-C. Sibuet, 2004: MicrOBS: A new generation of ocean bottom seismometer. First Break, 22, 41-47, doi: 10.3997/1365-2397.2004012. [Link]

Borcherdt, R. D., 1970: Effects of local geology on ground motion near San Francisco Bay. Bull. Seismol. Soc. Am., 60, 29-61.

Bour, M., D. Fouissac, P. Dominique, and C. Martin, 1998: On the use of microtremor recordings in seismic microzonation. Soil Dyn. Earthq. Eng., 17, 465-474, doi: 10.1016/S0267-7261(98)00014-1. [Link]

Chen, S.-C., S.-K. Hsu, C.-H. Tsai, C.-Y. Ku, Y.-C. Yeh, and Y. Wang, 2010: Gas seepage, pockmarks and mud volcanoes in the near shore of SW Taiwan. Mar. Geophys. Res., 31, 133-147, doi: 10.1007/s11001-0109097-6. [Link]

Chen, S.-C., S.-K. Hsu, Y. Wang, S.-H. Chung, P.-C. Chen, C.-H. Tsai, C.-S. Liu, H.-S. Lin, and Y.-W. Lee, 2014: Distribution and characters of the mud diapirs and mud volcanoes off southwest Taiwan. J. Asian Earth Sci., 92, 201-214, doi: 10.1016/j.jseaes.2013.10.009. [Link]

Cheng, W. B., T. Y. Shih, W. Y. Lin, T. K. Wang, C. S. Liu, and Y. Wang, 2014: Imaging seismic velocities for hydrate-bearing sediments using converted waves near Yuan-An Ridge, off southwest Taiwan. J. Asian Earth Sci., 92, 215-223, doi: 10.1016/j.jseaes.2013.10.013. [Link]

Chiang, C.-S. and H.-S. Yu, 2006: Morphotectonics and incision of the Kaoping submarine canyon, SW Taiwan orogenic wedge. Geomorphology, 80, 199-213, doi: 10.1016/j.geomorph.2006.02.008. [Link]

Chiu, J. K., W. H. Tseng, and C. S. Liu, 2006: Distribution of gassy sediments and mud volcanoes offshore southwestern Taiwan. Terr. Atmos. Ocean. Sci., 17, 703722, doi: 10.3319/TAO.2006.17.4.703(GH). [Link]

Chuang, P. C., T. F. Yang, S. Lin, H. Lee, T. F. Lan, W.
Hong, C. Liu, J. Chen, and Y. Wang, 2006: Extremely high methane concentration in bottom water and cored sediments from offshore southwestern Taiwan. Terr. Atmos. Ocean. Sci., 17, 903-920, doi: 10.3319/ TAO.2006.17.4.903(GH). [Link]

Dobry, R., I. Oweis, and A. Urzua, 1976: Simplified procedures for estimating the fundamental period of a soil profile. Bull. Seismol. Soc. Am., 66, 1293-1321.

Doo, W.-B., S.-K. Hsu, C.-L. Lo, S.-C. Chen, C.-H. Tsai, J.-Y. Lin, Y.-P. Huang, Y.-S. Huang, S.-D. Chiu, and Y.-F. Ma, 2015: Gravity anomalies of the active mud diapirs off southwest Taiwan. Geophys. J. Int., 203, 2089-2098, doi: 10.1093/gji/ggv430. [Link]

Fäh, D., F. Kind, and D. Giardini, 2001: A theoretical investigation of average $\mathrm{H} / \mathrm{V}$ ratios. Geophys. J. Int., 145, 535-549, doi: 10.1046/j.0956-540x.2001.01406.x. [Link]

Field, E. H. and K. H. Jacob, 1995: A comparison and test of various site-response estimation techniques, including three that are not reference-site dependent. Bull. Seismol. Soc. Am., 85, 1127-1143.

Haacke, R. R., G. K. Westbrook, and M. S. Riley, 2008: Controls on the formation and stability of gas hydrate-related bottom-simulating reflectors (BSRs): A case study from the west Svalbard continental slope. J. Geophys. Res., 113, B05104, doi: 10.1029/2007JB005200. [Link]

Hsiao, N.-C., T.-W. Lin, S.-K. Hsu, K.-W. Kuo, T.-C. Shin, and P.-L. Leu, 2014: Improvement of earthquake locations with the Marine Cable Hosted Observatory (MACHO) offshore NE Taiwan. Mar. Geophys. Res., 35, 327-336, doi: 10.1007/s11001-013-9207-3. [Link]

Hsu, S. K., J. Kuo, C. L. Lo, C. H. Tsai, W. B. Doo, C. Y. $\mathrm{Ku}$, and J. C. Sibuet, 2008: Turbidity currents, submarine landslides and the 2006 Pingtung earthquake off SW Taiwan. Terr. Atmos. Ocean. Sci., 19, 767-772, doi: 10.3319/TAO.2008.19.6.767(PT). [Link]

Hu, C., 1988: Basement structure and the Oligocene to Miocene stratigraphy of the Tainan Basin. Petroleum, 24, 104-115.

Huang, B. S., 2000: Two-dimensional reconstruction of the surface ground motions of an earthquake: The September 21, 1999, Chi-Chi, Taiwan earthquake. Geophys. Res. Lett., 27, 3025-3028, doi: 10.1029/2000g1011481. [Link]

Huang, H. C., 2002: Characteristics of earthquake ground motions and the $\mathrm{H} / \mathrm{V}$ of microtremors in the southwestern part of Taiwan. Earthq. Eng. Struct. Dyn., 31, 1815-1829, doi: 10.1002/eqe.191. [Link]

Ibs-von Seht, M. and J. Wohlenberg, 1999: Microtremor measurements used to map thickness of soft sediments. Bull. Seismol. Soc. Am., 89, 250-259.

Jiang, W. T., J. C. Chen, B. J. Huang, C. J. Chen, Y. T. Lee, P. R. Huang, C. C. Lung, and S. W. Huang, 2006: Mineralogy and physical properties of cored sediments from 
the gas hydrate potential area of offshore southwestern Taiwan. Terr. Atmos. Ocean. Sci., 17, 981-1007, doi: 10.3319/TAO.2006.17.4.981(GH). [Link]

Johnson, L. R. and W. Silva, 1981: The effects of unconsolidated sediments upon the ground motion during local earthquakes. Bull. Seismol. Soc. Am., 71, 127-142.

Kayen, R. E. and H. J. Lee, 1991: Pleistocene slope instability of gas hydrate-laden sediment on the Beaufort sea margin. Mar. Geotech., 10, 125-141, doi: 10.1080/10641199109379886. [Link]

Koketsu, K. and M. Kikuchi, 2000: Propagation of seismic ground motion in the Kanto basin, Japan. Science, 288, 1237-1239, doi: 10.1126/science.288.5469.1237. [Link]

Komatitsch, D., Q. Liu, J. Tromp, P. Süss, C. Stidham, and J. H. Shaw, 2004: Simulations of ground motion in the Los Angeles basin based upon the spectral-element method. Bull. Seismol. Soc. Am., 94, 187-206, doi: 10.1785/0120030077. [Link]

Kuo, C. H., K. L. Wen, C. M. Lin, S. Wen, and J. Y. Huang, 2015: Investigating Near Surface S-wave Velocity Properties Using Ambient Noise in Southwestern Taiwan. Terr. Atmos. Ocean. Sci., 26, 205-211, doi: 10.3319/TAO.2014.12.02.05(EOSI). [Link]

LeBrun, B., A.-M. Duval, P.-Y. Bard, O. Monge, M. Bour, S. Vidal, and H. Fabriol, 2004: Seismic microzonation: A comparison between geotechnical and seismological approaches in Pointe-à-Pitre (French West Indies). Bull. Earthq. Eng., 2, 27-50, doi: 10.1023/b:beee.0000 038949.91495.91. [Link]

Lee, C.-T., C.-T. Cheng, C.-W. Liao, and Y.-B. Tsai, 2001: Site classification of Taiwan free-field strong-motion stations. Bull. Seismol. Soc. Am., 91, 1283-1297, doi: 10.1785/0120000736. [Link]

Lee, S.-J., Y.-C. Chan, D. Komatitsch, B.-S. Huang, and J. Tromp, 2009: Effects of realistic surface topography on seismic ground motion in the Yangminshan region of Taiwan based upon the spectral-element method and LiDAR DTM. Bull. Seismol. Soc. Am., 99, 681-693, doi: 10.1785/0120080264. [Link]

Lermo, J. and F. J. Chávez-García, 1993: Site effect evaluation using spectral ratios with only one station. Bull. Seismol. Soc. Am., 83, 1574-1594.

Lin, A. T., C.-S. Liu, C.-C. Lin, P. Schnurle, G.-Y. Chen, W.-Z. Liao, L. S. Teng, H.-J. Chuang, and M.-S. Wu, 2008: Tectonic features associated with the overriding of an accretionary wedge on top of a rifted continental margin: an example from Taiwan. Mar. Geol., 255, 186-203, doi: 10.1016/j.margeo.2008.10.002. [Link]

Lin, C.-C., A. T.-S. Lin, C.-S. Liu, G.-Y. Chen, W .-Z. Liao, and P. Schnurle, 2009: Geological controls on BSR occurrences in the incipient arc-continent collision zone off southwest Taiwan. Mar. Petrol. Geol., 26, 11181131, doi: 10.1016/j.marpetgeo.2008.11.002. [Link]
Lin, J.-Y., W.-N. Wu, and C.-L. Lo, 2015: Megathrust earthquake potential of the Manila subduction systems revealed by the radial component of seismic moment tensors Mrr. Terr. Atmos. Ocean. Sci., 26, 619-630, doi: 10.3319/TAO.2013.04.29.01(TC). [Link]

Liu, C.-S., I. L. Huang, and L. S. Teng, 1997: Structural features off southwestern Taiwan. Mar. Geol., 137, 305319, doi: 10.1016/s0025-3227(96)00093-x. [Link]

Liu, C.-S., B. Deffontaines, C.-Y. Lu, and S. Lallemand, 2004: Deformation patterns of an accretionary wedge in the transition zone from subduction to collision offshore southwestern Taiwan. Mar. Geophys. Res., 25, 123-137, doi: 10.1007/s11001-005-0738-0. [Link]

Liu, C.-S., P. Schnurle, Y. Wang, S. H. Chung, S. C. Chen, and T. H. Hsiuan, 2006: Distribution and characters of gas hydrate offshore of southwestern Taiwan. Terr. Atmos. Ocean. Sci., 17, 615-644, doi: 10.3319/ TAO.2006.17.4.615(GH). [Link]

Malischewsky, P. G. and F. Scherbaum, 2004: Love's formula and H/V-ratio (ellipticity) of Rayleigh waves. Wave motion, 40, 57-67, doi: 10.1016/j.wavemoti.2003.12.015. [Link]

Mienert, J., M. Vanneste, S. Bünz, K. Andreassen, H. Haflidason, and H. P. Sejrup, 2005: Ocean warming and gas hydrate stability on the mid-Norwegian margin at the Storegga Slide. Mar. Petrol. Geol., 22, 233-244, doi: 10.1016/j.marpetgeo.2004.10.018. [Link]

Nakamura, Y., 1989: A method for dynamic characteristics estimation of subsurface using microtremor on the ground surface. Railway Technical Research Institute, Quarterly Reports 30.

Reed, D. L., N. Lundberg, C.-S. Liu, and B.-Y. Kuo, 1992: Structural Relations along the Margins of the Offshore Taiwan Accretionary Wedge: Implications for Accretion and Crustal Kinematics. Science Reports of the National Taiwan University ACTA Geologica Taiwanica, 30, 105-122.

Scherbaum, F., K. G. Hinzen, and M. Ohrnberger, 2003: Determination of Shallow Shear Wave Velocity Profiles in the Cologne, Germany Area Using Ambient Vibrations. Geophys. J. Int., 152, 597-612, doi: 10.1046/j.1365-246x.2003.01856.x. [Link]

Sokolov, V. Y., C.-H. Loh, and W.-Y. Jean, 2007: Application of horizontal-to-vertical (H/V) Fourier spectral ratio for analysis of site effect on rock (NEHRP-class B) sites in Taiwan. Soil Dyn. Earthq. Eng., 27, 314-323, doi: 10.1016/j.soildyn.2006.09.001. [Link]

Sokolov, V., K. L. Wen, J. Miksat, F. Wenzel, and C. T. Chen, 2009: Analysis of Taipei basin response for earthquakes of various depths and locations using empirical data.Terr. Atmos. Ocean. Sci., 20, 687-702, doi: 10.3319/TAO.2008.10.15.01(T). [Link]

Su, C.-C., S.-T. Hsu, H.-H. Hsu, J.-Y. Lin, and J.-J. Dong, 2016: Spatial distribution of sedimentological 
characteristics and seafloor failure evaluation offshore SW Taiwan. 2016 Taiwan Geosciences Assembly, abstract NH4-2A-04.

Sultan, N., P. Cochonat, J.-P. Foucher, and J. Mienert, 2004: Effect of gas hydrates melting on seafloor slope instability. Mar. Geol., 213, 379-401, doi: 10.1016/j.margeo.2004.10.015. [Link]

Sun, S., 1982: The Tertiary basins of offshore Taiwan, Proceedings of the second ASCOPE Conference and Exhibition, 125-135.

Sun, S. and C. Liu, 1993: Mud diapirs and submarine channel deposits in offshore Kaohsiung-Hengchun, southwest Taiwan. Petrol. Geol. Taiwan, 28, 1-14.

Teves-Costa, P., L. Matias, and P. Y. Bard, 1996: Seismic behaviour estimation of thin alluvium layers using microtremor recordings. Soil Dyn. Earthq. Eng., 15, 201209, doi: 10.1016/0267-7261(95)00038-0. [Link]

Wen, K.-L., 1994: Non-linear soil response in ground motions. Earthq. Eng. Struct. Dyn., 23, 599-608, doi: 10.1002/eqe.4290230603. [Link]

Wen, K.-L. and H.-Y. Peng, 1998: Site effect analysis in the Taipei basin: Results from TSMIP network data.
Terr. Atmos. Ocean. Sci., 9, 691-704, doi: 10.3319/ TAO.1998.9.4.691(T). [Link]

Yamanaka, H., M. Takemura, H. Ishida, and M. Niwa, 1994: Characteristics of long-period microtremors and their applicability in exploration of deep sedimentary layers. Bull. Seismol. Soc. Am., 84, 1831-1841.

Yang, K. M., H. H. Ting, and J. Yuan, 1991: Structural styles and tectonic modes of Neogene extensional tectonics in southwestern Taiwan: Implications for hydrocarbon exploration. Petrol. Geol. Taiwan, 26, 1-31.

Yang, T. F., P. C. Chuang, S. Lin, J. C. Chen, Y. Wang, and S. H. Chung, 2006: Methane venting in gas hydrate potential area offshore of SW Taiwan: evidence of gas analysis of water column samples. Terr. Atmos. Ocean. Sci., 17, 933-950, doi: 10.3319/ TAO.2006.17.4.933(GH). [Link]

Zhao, J. X., K. Irikura, J. Zhang, Y. Fukushima, P. G. Somerville, A. Asano, Y. Ohno, T. Oouchi, T. Takahashi, and H. Ogawa, 2006: An empirical site-classification method for strong-motion stations in Japan using H/V response spectral ratio. Bull. Seismol. Soc. Am., 96, 914-925, doi: 10.1785/0120050124. [Link] 